\title{
CONTROLE ALTERNATIVO DE PRAGAS E DOENÇAS PELOS HORTICULTORES DA ZONA URBANA DE BOA VISTA-RR
}

\section{ALTERNATIVE PEST AND DISEASE CONTROL BY HORTICULTURISTS IN THE URBAN AREA OF BOA VISTA-RR}

Washington Pereira de Carvalho ${ }^{1}$

Edgley Soares da Silva ${ }^{2}$

RESUMO: Objetivou-se com esse trabalho, avaliar o perfil do uso do controle alternativo de pragas e doenças pelos horticultores da zona urbana de Boa Vista, Roraima, Brasil. O levantamento foi realizado nos bairros produtores, onde o método de avaliação empregado foi a pesquisa de campo, com entrevista a 30 horticultores. Observou-se que $80 \%$ afirmaram conhecer ou já ter ouvido falar no Controle Alternativo de Pragas e Doenças (CAPD) e que 47\% destes, utilizam somente o CAPD. O controle cultural em conjunto com o controle químico sintético é a forma mais empregada, com percentual de 36,7\%. A rotação de cultura foi realizada por $100 \%$ dos produtores. A Couve (Brassica oleracea var. acephala) foi citada como a hortaliça mais atacada por pragas e doenças. O Pulgão (Hemiptera: Aphididae) foi apontado como a principal praga das hortaliças na zona urbana de Boa Vista. Concluiu-se que os produtores de hortaliças da zona urbana de Boa Vista-RR têm conhecimento sobre o uso do Controle Alterativo de Pragas e Doenças, porém, não utilizam devido a dificuldade de implementação dessa prática e a baixa eficiência no controle. A rotação de cultura é o principal tipo de Controle Alterativo de Pragas e Doenças utilizado pelos produtores da zona urbana de Boa Vista-RR. A maioria dos produtores urbanos de Boa Vista-RR não faz aplicação de produtos naturais alternativos no controle de pragas e doenças em suas hortas, no entanto, os que fazem utilizam principalmente urina de vaca e calda de fumo.

Palavras-chave: Agroecologia, Entomologia, Fitopatologia, Hortas Urbanas.
ABSTRACT: The objective of this work was to evaluate the profile of the use of alternative pest and disease control by horticulturists in the urban area of Boa Vista, Roraima, Brazil. The survey was carried out in the producing neighborhoods, where the evaluation method used was field research, with interviews with 30 horticulturists. It was observed that $80 \%$ claimed to know or have heard of Alternative Pest and Disease Control (CAPD) and that $47 \%$ of these use only CAPD. Cultural control together with synthetic chemical control is the most used form, with a percentage of $36.7 \%$. The crop rotation was carried out by $100 \%$ of the producers. The Kale (Brassica oleracea var. Acephala) was cited as the vegetable most attacked by pests and diseases. The aphid (Hemiptera: Aphididae) was identified as the main pest of vegetables in the urban area of Boa Vista. It was concluded that vegetable producers in the urban area of Boa Vista-RR are aware of the use of Alterative Pest and Disease Control, however, they do not use it due to the difficulty of implementing this practice and the low efficiency in control. Crop rotation is the main type of Alterative Control of Pests and Diseases used by producers in the urban area of Boa Vista-RR. Most urban producers in Boa Vista-RR do not apply alternative natural products to control pests and diseases in their gardens, however, those who do mainly use cow urine and smoke syrup.

Keywords: Agroecology, Entomology, Phytopathology, Urban Gardens. 


\section{INTRODUÇÃO}

Inquietações remotas referentes ao desenvolvimento equilibrado envolvendo produção e sustentabilidade permeiam debates no mundo acadêmico e no cotidiano dos produtores. É importante estimular pesquisas e uso de práticas sustentáveis que não agridam a natureza e assegurem a saúde do agricultor e consumidor final (SEUFERT et al., 2012; SARTORI et al., 2014).

O desenvolvimento de modelos de produção agrícola de base ecológica tornou-se necessário para suprir a necessidade crescente de alimentos livres de resíduos tóxicos e ao mesmo tempo, respeitar os preceitos da sustentabilidade, da conservação do meio ambiente e do bem-estar do ser humano. Atualmente é possível utilizar de meios de produções eficazes que agreguem sustentabilidade econômica, social e ambiental aos produtos ofertados. Dentre os meios, podemos destacar o Controle Alternativo de Pragas e Doenças (CAPD), utilizado em várias culturas, sobretudo, hortaliças, severamente atacadas por uma infinidade de pragas e doenças (SOUSA et al., 2012; HEINEMANN et al., 2014; SARTORI et al., 2014).

O CAPD busca o uso de meios naturais e alternativos que garantam a produtividade econômica das culturas sem causar danos expressivos ao solo, à água e a qualidade dos alimentos. Neste sistema de produção o controle de doenças e pragas deve ser feito sem o uso de agrotóxicos sintéticos, dando preferência aos defensivos alternativos com aspecto de repelência, atração, inseticida e fungicida, cuja função é contribuir para o equilíbrio entre doenças, pragas e seus inimigos naturais (CORREAA; SALGADO, 2011; COUTINHO et al., 2011).

Os defensivos alternativos têm como características principais, baixa ou nenhuma toxicidade ao homem e à natureza, eficiência no combate a pragas em geral, não favorecimento à ocorrência de formas de resistência, boa disponibilidade e custo reduzido. Estão incluídos nesta categoria os agentes de biocontrole, os biofertilizantes líquidos, as caldas sulfocálcica, viçosa e bordalesa, os feromônios, os extratos de plantas, entre outros (HENZ et al., 2007; FERNANDES, 2013).

Com o advento do crescimento populacional e a expansão das grandes cidades, os produtores de hortaliças viram a oportunidade de se instalar e produzir alimento próximo do mercado consumidor, passando a estabelecer suas hortas nos bairros periféricos das cidades. Entretanto, a produção urbana de hortaliças trouxe consigo uma série de cuidados a serem tomados, sobretudo, com uso de defensivos químicos, pois quando aplicados de maneira inadequada, acarretam diretamente a saúde da população no seu entorno (AQUINO; ASSIS, 2007; ALVES et. al., 2013; PIRES, 2016).

O CAPD surge então como oportunidade de ser utilizado por produtores de hortaliças em zonas urbanas, de modo a preservar o meio ambiente e a saúde humana local. É sabido que alguns produtores de hortaliças da zona urbana de Boa Vista-RR fazem uso do controle alternativo de pragas e doenças, porém, não se tem um diagnóstico detalhado sobre 
quais os tipos e formas de utilização desse método. Nesse sentido, objetivou-se com este trabalho, avaliar o perfil de uso do controle alternativo de pragas e doenças pelos horticultores da zona urbana de Boa Vista, Roraima, Brasil.

\section{MATERIAL E MÉTODOS}

O levantamento foi realizado no período de 15 a 22 de março de 2019, em hortas urbanas localizadas na cidade de Boa Vista, Roraima, Brasil. Os bairros onde o levantamento foi realizado foram: Operário, Professora Araceli Souto Maior, Jardim Tropical, Jardim Primavera, Senador Hélio Campos e Nova Cidade.

Foram selecionadas todas as propriedades da zona urbana que se tinha conhecimento de haver produção de hortaliças, fossem estas vinculadas às ações da prefeitura municipal de Boa Vista, instituições religiosas ou particulares, o que totalizou 30 estabelecimentos.

A entrevista aberta e individual foi a estratégia de produção de dados para esta investigação, através de estudo exploratório quantitativo. Foram entrevistados 30 horticultores (um em cada propriedade), que espontaneamente de dispuseram a participar da pesquisa. $\mathrm{O}$ instrumento utilizado para coleta de dados foi um questionário composto de 10 perguntas previamente elaboradas referente ao tema de estudo. Tratou-se de perguntas fechadas em que o entrevistador fazia a pergunta e o produtor apenas respondia uma ou mais das alternativas expostas. A saber o teor: qual bairro se encontrava a horta? Qual o tempo de atividade? Se conhecia o CAPD? Se fazia uso apenas do CAPD ou utilizava também controle químico? Quais os métodos de controle de pragas e doenças mais utilizados? Quais os tipos de controle de pragas e doenças mais utilizados? Quais os produtos mais utilizados no CAPD? Quais as principais hortaliças produzidas? Quais as hortaliças mais atacadas por pragas e/ou doenças? e quais as principais pragas e doenças presentes nas hortas?

Todas as entrevistas ocorreram in loco, em contato direto com os horticultores, os quais interagiram, interpretaram, construíram sentidos e significados para as perguntas. Todavia, procurou-se trabalhar com a objetividade dos fatos para compreender e analisar os dados.

As perguntas selecionadas para serem aplicadas aos horticultores apresentaram riscos mínimos de possibilidade de constrangimento, contrariedade e desconforto, sejam de natureza psíquica, social e cultural. Contudo, ainda assim, assinaram termos de anuência em participação na pesquisa.

Cada produtor respondeu ao questionário e ao final foi gerado um conjunto de informações que foram plotadas em planilhas para posterior confecção de gráficos de resposta.

A análise dos dados foi realizada através de percentagem simples.

\section{RESULTADOS E DISCUSSÃO}

O bairro Operário ocupou o primeiro lugar na concentração da produção de hortaliça na zona urbana de Boa Vista, concentrando 76,66\% dos produtores, em seguida, mas com percentagem bem abaixo, vem o bairro Araceli, com 6,66\% (Figura 1). 


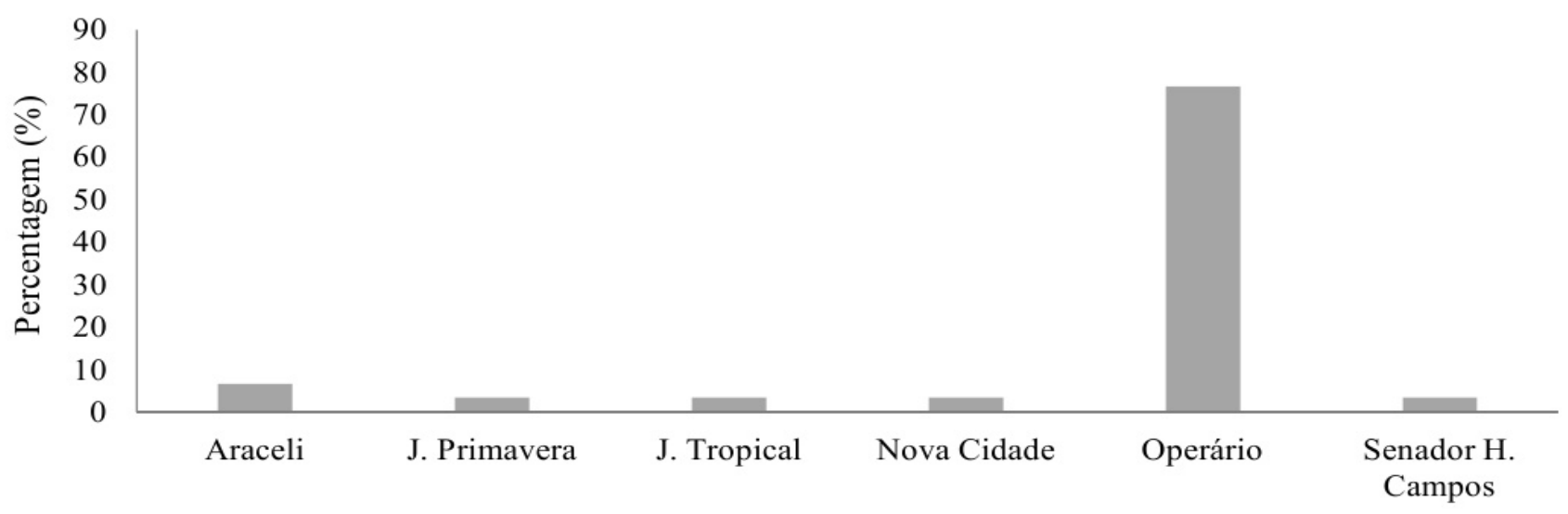

Figura 1: Distribuição dos produtores de hortaliças por bairros da zona urbana de Boa Vista-RR, 2019. Fonte: Elaborada pelos autores (2020).

O bairro Operário localiza-se geograficamente no setor Oeste de Boa Vista-RR, à aproximadamente $14 \mathrm{~km}$ do centro da cidade. O bairro é tradicionalmente conhecido como região de concentrações de chácaras e com grande número de olericultores inseridos no perímetro urbano de Boa Vista-RR, sendo a horticultura umas das principais atividades dos moradores, que contribuem para o abastecimento do mercado local (PORTELA; VILHENA JÚNIOR, 2008).

Durante a condução da pesquisa conheceu-se a dimensão e capacidade de produção de hortaliças no bairro Operário, demostrando sua importância dentro da agricultura urbana praticada em Boa Vista. Os demais bairros, de menor expressão produtiva, têm também sua relevância, pois contribuem consideravelmente para en

fatizam a dinâmica das hortas urbanas, onde a comercialização é feita principalmente in loco e também em pequenos mercados, feiras livres e restaurantes situados no meio urbano.

O cultivo de hortaliças na zona urbana de Boa Vista-RR, é praticado, sobretudo, por produtores com tempo de atividade menor ou igual a cinco anos, com participação de 33,33\% do total. O menor percentual foi verificado naqueles que há mais de 20 anos cultivam hortaliças, chegando a 13,33\% de participação, conforme figura 2.

Apesar do grande percentual de produtores exercerem atividade como horticultores por menor tempo, muitos desses já demonstram desânimo em continuar com o cultivo, alegando cansaço,

$\begin{array}{lr}\text { abastecer } & \text { a } \\ \text { população } & \\ \text { circunvizinha } & \text { que } \\ \text { compram } & \\ \text { diretamente nas } \\ \text { hortas onde preços } \\ \text { geralmenter são } \\ \text { acessíveis. Santana } \\ \text { et al. (2017) }\end{array}$

et al. (2017)

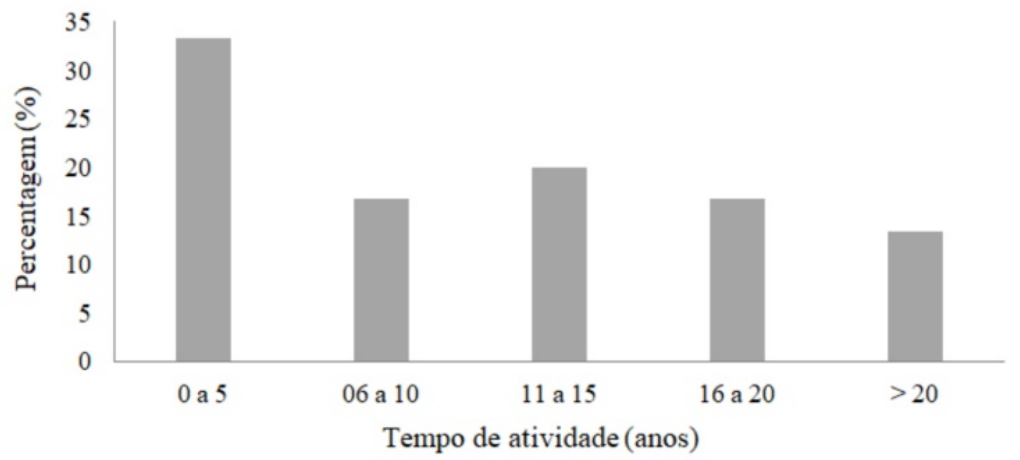

Figura 2: Tempo de atividade dos produtores de hortaliças da zona urbana de Boa Vista, RR, 2019. Fonte: Elaborada pelos autores (2020). 
baixa lucratividade, ausência de assistência técnica, dificuldades financeiras para implantar novas tecnologias nas hortas, difícil controle de pragas e doenças e, sobretudo, necessidade constante de mãode-obra, fatores estes que corroboram com Barth et al. (2016), ao afirmarem que a agricultura de pequeno porte, a exemplo da urbana, caracteriza-se pela pouca automatização de seus processos, fato que demanda cargas excessivas de trabalho em seus praticantes.

Observou-se que a maioria dos produtores são senhores de idade mais avançada, demostrando que mesmo em ambiente urbano, os mais jovens não participam dessa atividade e que há pouco interesse dos filhos dos produtores em seguir a profissão do pai. Prevalece por parte dos jovens a ideia de que a atividade agrícola é desvalorizada e propicia poucos benefícios para seus praticantes, como citam Troian e Breitenbach (2018). Adotase como pressuposto que essa mesma lógica sucessória se reproduza no meio urbano.

Vale salientar que todos os produtores são do sexo masculino. De acordo com Schmitz e Santos (2014), essa supremacia masculina acontece devido ao trabalho na agricultura ainda reproduzir a estrutura patriarcal da família. O patriarcado atribui ao homem o papel de protagonista no processo de produção agrícola e desvaloriza o trabalho da mulher. Contudo, estudos realizados em hortas urbanas e periurbanas retratam um novo cenário, onde prevalece o equilíbrio na divisão do trabalho entre homens e mulheres (OTTMANN et al., 2010; PRIMO et al., 2014).
Quando se indagou sobre o conhecimento dos mesmos quanto ao CAPD, $80 \%$ dos entrevistados afirmaram conhecer ou já ter ouvido falar e $20 \%$ afirmaram não conhecer ou nunca ouviram falar.

Apesar de 20\% dos produtores afirmarem não conhecer ou nunca terem ouvido falar do CAPD, no desenvolvimento da pesquisa constatou-se que $100 \%$ dos produtores utilizam algum meio de CAPD em suas hortas, mas não possuem conhecimentos técnicos para identificar qual ou quais são.

O uso apenas do CAPD como meio de controle é relevante entre os horticultores. Constatou-se que $47 \%$ dos produtores utilizam apenas o CAPD no controle de pragas e doenças, contudo utilizam sem conhecimento da real importância, devido, sobretudo a falta de assistência técnica. Esse contexto distingue do que propõe o controle alternativo de pragas e doenças, fundamentado nos conhecimentos técnico/ científicos sobre o cultivo ecológico, que tem diretrizes no uso de práticas preventivas iniciando com planejamento e diversificação do sistema (SOUZA, 2015).

Observou-se que 53\% dos produtores utilizam o CAPD em conjunto com o controle químico sintético, isso mostra que $100 \%$ dos produtores fazem uso em algum momento do CAPD, já que o restante dos entrevistados (47\%) utilizam CAPD isoladamente. Isso traz um cenário positivo no tocante à qualidade de vida dos horticultores e na qualidade das hortaliças produzidas na cidade. Mzoughi (2014) observa em seu estudo que os produtores quando aderem ao CAPD, buscam, 
sobretudo por bem estar, qualidade de vida, felicidade, saúde, reconhecimento social, satisfação no trabalho e lucratividade.

Os produtores utilizam pelo menos oito métodos para o controle de pragas e doenças, sendo o cultural em conjunto com o químico sintético, o mais utilizado, com $36,7 \%$ da preferência dos produtores, seguido do controle cultural em conjunto com o químico natural com 26,7\%. Aqueles que utilizam apenas o controle cultural representam $13,3 \%$, os que utilizam em conjunto os meios cultural, químico sintético e físico, perfazem 6,7\%, enquanto que os outros meios representam 3,3\% cada (Figura 3).

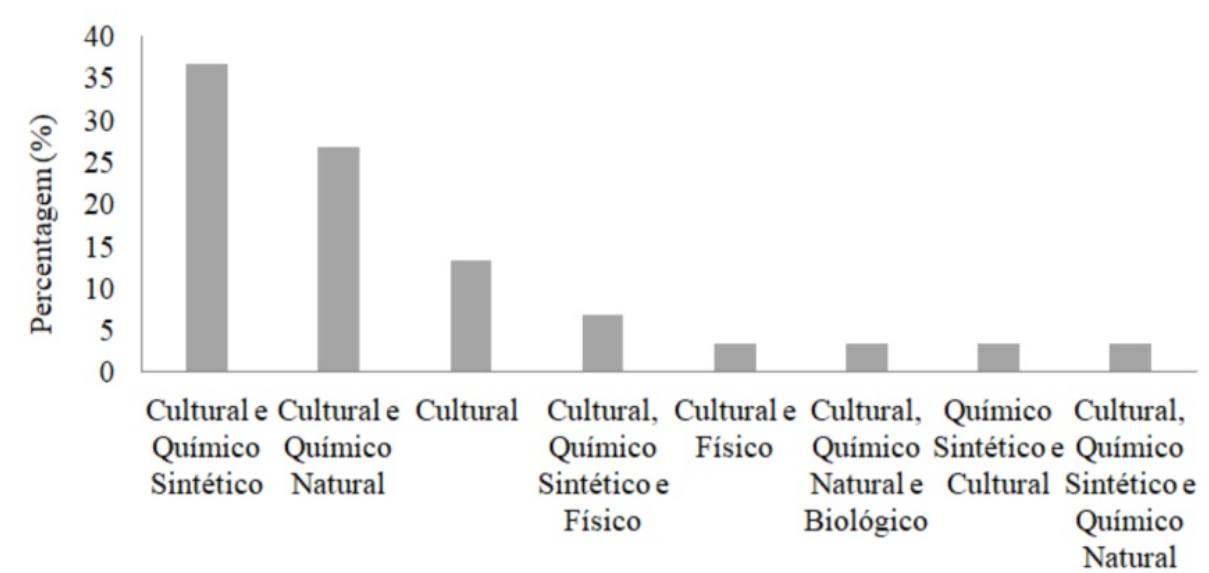

Figura 3: Métodos de controle de pragas e doenças utilizados pelos produtores de hortaliças da zona urbana de Boa Vista-RR.

Fonte: Elaborada pelos autores (2020).

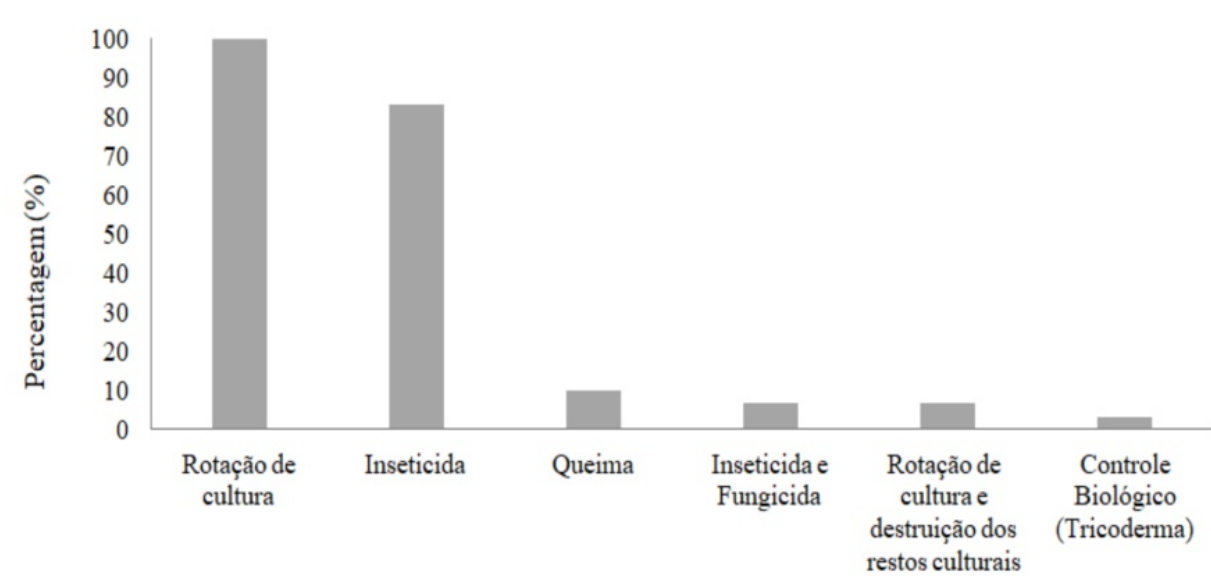

Figura 4: Tipos de controles de pragas e doenças mais utilizados pelos produtores de hortaliças da zona urbana de Boa Vista-RR.

Fonte: Elaborada pelos autores (2020).
Pode-se observar que o controle cultural, mais especificamente a rotação de cultura, é unanimidade entre os horticultores. Apesar de alguns produtores mostrarem desconhecimento que se trata de um tipo de CAPD, ao mesmo tempo afirmam que sem ele, não conseguem produzir com qualidade para fins comerciais.

São seis os tipos de controle utilizados pelos horticultores, sendo a rotação de cultura o mais expressivo, com 100\% da preferência dos produtores, seguido pelos inseticidas com $83,3 \%$ e queima de casca de arroz nos canteiros com $10 \%$. Vale destacar que apenas 3,3\% dos produtores fazem controle biológico de pragas e doenças, que em número real, representa um produtor que usa Tricoderma (Figura 4). O fato da rotação de cultura estar no topo da preferência dos produtores, não necessariamente significa que ela atinge todo seu potencial no combate às pragas e doenças presentes nos cultivos.

Constatou-se que os inseticidas utilizados pelos horticultores nem sempre são específicos ou recomendados para o controle de pragas e doenças em vegetais, alguns produtores informaram que fazem uso de produtos 
comerciais de uso
veterinário, tais como: Barrage $^{\circledR}$ e Butox ${ }^{\circledR}$,
indicados para o controle
de moscas e carrapatos
em animais e
estritamente proibidos
na agricultura.

$61,7 \%$ dos produtores não utilizam nenhum produto/substância no controle de pragas e Fonte: Elaborada pelos autores (2020).

doenças em suas hortas, são aqueles que fazem apenas rotação de cultura e queima. No entanto, quando se considera produtores que enquadram dentro dos $47 \%$ que utilizam apenas o CAPD como método de controle de pragas e doenças, $19,3 \%$ informaram utilizar como principal produto, urina de vaca e $10,4 \%$ calda de fumo, para repelir, sobretudo, pulgão, mosca branca e cochonilha (Figura 5). Sousa et al. (2012) citam que os extratos vegetais são maioria entre os controles alternativos utilizados em Alagoas, fato este que não ficou constatado quando comparado à zona urbana de Boa Vista-RR.

Os horticultores enfatizam que o difícil acesso, o alto custo, a falta de conhecimento, o difícil preparo das receitas/caldas/extratos e a baixa eficiência são as principais causas para o baixo índice do uso desses produtos. Tais informações corroboram com Venzon et al. (2010), em estudo com insumos alternativos para o controle de pragas e doenças. Por outro lado, aqueles que utilizam, ressaltam que a qualidade da produção é superior quando comparada aos que utilizam produtos químicos, salientam ainda que esses produtos não deixam resíduos no solo e praticamente eliminam riscos de intoxicação.

Constatou-se existir grande variedade de espécies de hortaliças cultivadas pelos produtores de Boa Vista-RR, com destaque para cebolinha (Allium schoenoprasum) cultivada em 96,7\% das propriedades, seguida por alface (Lactuca sativa) e coentro (Coriandrum sativum) com 93,3\% cada, couve (Brassica oleracea var. acephala) com 90\% e rúcula (Eruca vesicaria) com $60 \%$ (Figura 6 ).

Portela e Vilhena Júnior (2008), afirmaram em sua pesquisa, que o maior cultivo de hortaliças, como: alface, couve, cebolinha, coentro, entre outras, se dá ao fato de serem as mais vendidas nos mercados e feiras de Boa Vista-RR, e por serem mais consumidas pela população local.

Em estudo realizado na cidade de Santo Antônio do Descoberto (GO) foi verificado que a maior produção e consumo de hortaliça na região periférica da cidade, foi de alface e cebolinha. Constatou-se ainda que as hortaliças: feijão-vagem, espinafre, agrião, brócolis, 


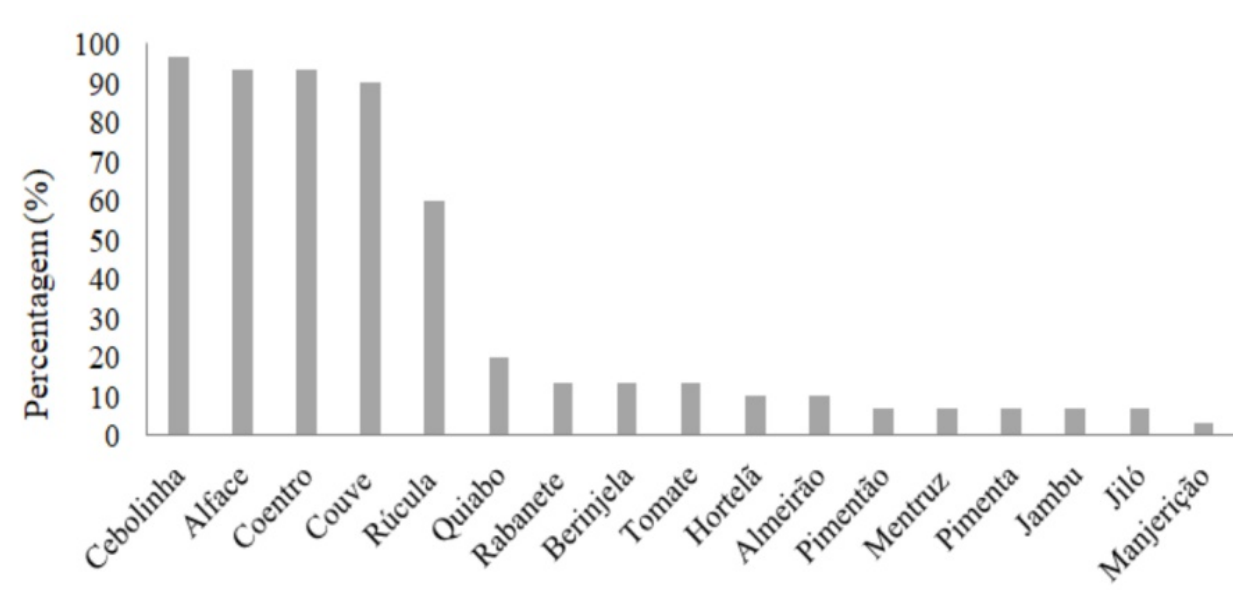

ataques nas hortas, seguido pela mosca branca (Hemiptera: Aleyrodidae) com 20\%, e a cochonilha (Hemiptera: coccidae) com $5 \%$, já quanto às doenças, as fúngicas foram as mais citadas com 5\% (Figura 8). Segundo relato dos Figura 6: Principais hortaliças cultivadas pelos produtores da zona urbana de Boa Vista-RR. Fonte: Elaborada pelos autores (2020).

produtores a couve é a espécie mais atacada mostarda, abobrinha, chuchu, pepino, quiabo e jiló são pouco produzidas e não são frequentemente consumidas pela população local, corroborando com os resultados obtidos no presente estudo (CASTELO BRANCO et al., 2006).

As principais hortaliças que sofrem com ataque de pragas e doenças são couve, alface e cebolinha. A couve é a cultura com maior percentual de ataques, com $60 \%$ da predileção das pragas e doenças, seguida pela alface (28\%) e cebolinha (8\%) (Figura 7).

A couve, apesar de ser a quarta por doenças, sobretudo na fase inicial de crescimento, o que perante visualização e descrição dos sintomas pareceu se tratar de mancha de alternaria (Alternaria brassicae) e míldio (Peronospora parasítica), as quais busca-se o controle com rotação de cultura.

O pulgão ocupou destaque de principal praga das hortaliças em Boa Vista-RR. Segundo os produtores a cultura preferida dessa praga é a couve. O pulgão é uma das principais pragas das hortaliças e quando não controlado de maneira eficaz causa sérios prejuízos (SOUSA et al., 2012). colocada na cadeia de produção, lidera a lista de preferência pelas pragas e doenças. $\mathrm{O}$ que chamou a atenção foi o baixo índice de ataques à cultura da cebolinha, que é líder em quantidade produzida.

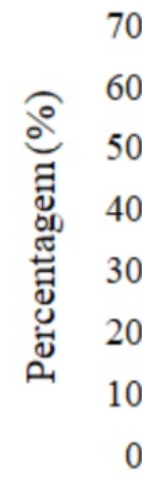

As principais pragas relatadas pelos Figura 7: Hortaliças mais atacadas por pragas e doenças na zona urbana de Boa Vista-RR. Fonte: Elaborada pelos autores (2020). produtores foram: o pulgão (Hemiptera: Aphididae) responsável por $67 \%$ dos 
alternativo de pragas e doenças deve ser utilizado como uma ferramenta a mais dentro de uma perspectiva ecológica de

produção. Ressaltamos ainda que esse controle deve ser pensado de modo sistêmico, considerando a cultura e o agroecossistema local, a maior intensificação possível do trabalho e menor de capital, a valorização

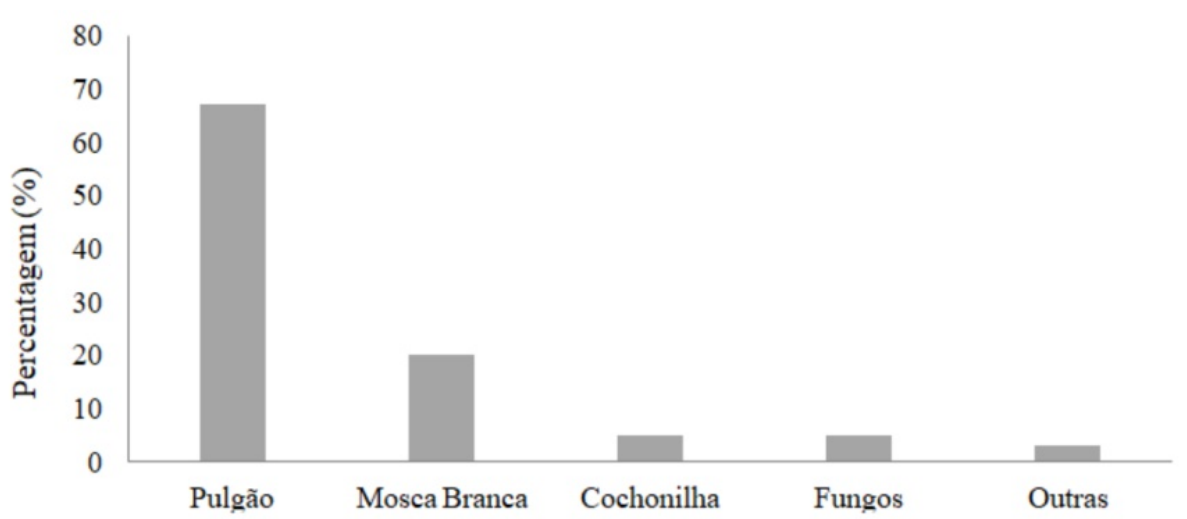
dos saberes e dos recursos genéticos locais, e a autonomia financeira dos agricultores.

\section{CONSIDERAÇÕES FINAIS}

Os produtores de hortaliças da zona urbana de Boa Vista-RR têm conhecimento sobre o uso do Controle Alterativo de Pragas e Doenças, porém, não utilizam devido à dificuldade de implementação dessa prática e a baixa eficiência no controle.

A rotação de cultura é o principal tipo de Controle Alterativo de Pragas e Doenças utilizado pelos produtores da zona urbana de Boa Vista-RR.

A maioria dos produtores urbanos de Boa Vista-RR não faz aplicação de produtos naturais alternativos no controle de pragas e doenças em suas hortas, no entanto, os que fazem utilizam principalmente urina de vaca e calda de fumo.
ALVES, J. D. N.; OLIVEIRA, S. S.; MOTA, A. M.; ALMEIDA, R. H. C.; OKUMURA, R. S. Percepção de riscos do uso de agrotóxicos na cultura da laranja pela comunidade do Cubiteua, município de Capitão Poço - PA. Enciclopédia Biosfera, v. 9, n. 17, p. 3594-3602, 2013. AQUINO, A. M. de; ASSIS, R. L. de. Agricultura orgânica em áreas urbanas e periurbanas com base em agroecologia. Ambiente \& Sociedade, v. 10, n. 1, p. 137-150, 2007.

BARTH, M.; RENNER, J. S.; MARTINS, R. L.; SILVA, D. R. Q. da. Agricultura Familiar: características ergonômicas das atividades e impactos na saúde dos trabalhadores. Estudos Sociedade e Agricultura, v. 24, n. 2, p. 471-496, 2016. CASTELO BRANCO, M.; NOGUEIRA, J. M.; SANTOS, R. C. Perfil dos consumidores de hortaliças da cidade de Santo Antônio do Descoberto-GO.

Horticultura Brasileira, v.24, n.3, p.68372, 2006. 
COITINHO, R. L. B. de C.; OLIVEIRA, J. V. de; GONDIM JUNIOR, M. G. C.; CAMARA, C. A. G. da. Toxicidade por fumigação, contato e ingestão de óleos essenciais para Sitophilus zeamais Motschulski, 1885 (Coleoptera: Curculionidade). Ciência e Agrotecnologia, v.35, n.1, p.172-178, 2011.

CORRÊA, J. C. R.; SALGADO, H. R. do $\mathrm{N}$. Atividade inseticida das plantas e aplicações: revisão. Revista Brasileira de Plantas Medicinais, v.13, n.4, p.500-506, 2011.

FERNANDES, M. do C. de A. Guia dos Defensivos Alternativos. Rio de Janeiro: CREA-RJ, 2013, 24 p.

HEINEMANN, J. A.; MASSARO, M.; CORAY, D. S.; AGAPITO-TENFEN, S. Z.; WEN, J. D. Sustainability and innovation in staple crop production in the US Midwest. International Journal of Agricultural Sustainability, v. 12, n. 1, p. 71-88, 2014.

HENZ, G. P.; ALCÂNTARA, F. A. de; RESENDE, F. V. Produção orgânica de hortaliças: o produtor pergunta, a Embrapa responde. Brasília: Embrapa Informação Tecnológico, 2007. 308 p.

MZOUGHI, N. Do organic farmers feel happier than conventional ones an exploratory analysis. Ecological

Economics, v. 103, n.1, p. 38-43, 2014.

OTTMANN, M. M. A.; BORCIONI, E.; MIELKE, É.; CRUZ, Ma. R. da; FONTE, N. N. da. Impactos ambientais e socioeconômicos em hortas comunitárias sob Linhas de Transmissão no Bairro Tatuquara, Curitiba, PR, Brasil. Revista Brasileira de Agroecologia, v. 5, n. 1, p.
86-94, 2010.

PIRES, V. C. Agricultura Urbana como Fator de Desenvolvimento Sustentável: Um Estudo na Região Metropolitana de Maringá. Revista Pesquisa \& Debate. v. 27. n. 2, p.69-84, 2016.

PORTELA, V. F.; VILHENA JÚNIOR, W. M. Agricultura familiar no centro urbano: a experiência do bairro operário em Boa Vista-Roraima. Revista Eletrônica de Ciências Sociais, v.1, n. 1, p. 1-17, 2008.

PRIMO, G. A.; FERREIRA, T. A.; PINTO, I. de O.; SANTOS, J. P.; FERREIRA, J. de S. Mapeamento e caracterização da agricultura urbana no município de Gurupi-TO. Revista Verde de Agroecologia e Desenvolvimento Sustentável, v. 9, n. 4, p. 212-219, 2014. SANTANA, M. C. de; LUZ, E. de S.; SILVA, M. R. da; SILVA, M. C.; CASAGRANDE JUNIOR, E. F. Trabalho do produtor agrícola urbano e periurbano: horticultores do centro-sul piauiense.

Sociedade e Território. v. 29, n. 2, p. 132153, 2017.

SARTORI, S.; DA SILVA, F. L.; CAMPOS, L. M. de S. Sustentabilidade e desenvolvimento sustentável: uma taxonomia no campo da literatura.

Ambiente \& Sociedade, v. 17, n. 1, p. 122, 2014.

SCHMITZ, A. M.; SANTOS, R. A. dos. A produção de leite na agricultura familiar do Sudoeste do Paraná e a participação das mulheres no processo produtivo.Terr@ Plural, v. 7, n. 2, p. 339-356, 2014.

SEUFERT, V.; RAMANKUTTY, N.; FOLEY, J. A. Comparing the yields of organic and conventional agriculture. Nature, v. 485, n. 7397, p. 229-232, 2012. 
SOUSA, A. A. de; AZEVEDO, E. de; LIMA, E. E. de; SILVA, A. P. F. da.

Alimentos Orgânicos e Saúde Humana:

Estudo sobre as controvérsias, Revista

Panamericana de Salud Publica, v. 31, n.

6, 513-517, 2012.

SOUZA, J. Agricultura orgânica:

tecnologias para a produção de

alimentos. v.3. Vitória: Incaper, 2015. 373

p.

TROIAN, A.; BREITENBACH, R. Jovens e juventudes em estudos rurais do Brasil. Interações, v. 19, n. 4, p. 789-802, 2018.

VENZON, M.; PAULA JUNIOR, T. J. de; PINTO, C. M. F.; OLIVEIRA, R. M. de; BONOMO, Í. S. Insumos alternativos para o controle de pragas e doenças. Informe Agropecuário, v. 31, n.2, p. 108-115, 2010. 